\title{
Differences in the diagnosis of primary cutaneous melanoma in the public and private healthcare systems in Joinville, Santa Catarina State, Brazil ${ }^{*}$
}

\author{
Raquel Bissacotti Steglich ${ }^{1}$, Silvana Cardoso², Maria Helena da Costa Naumann Gaertner², Karina \\ Munhoz de Paula Alves Coelho ${ }^{3}$, Tania Ferreira Cestari ${ }^{4}$, Selma Cristina Franco ${ }^{3}$
}

DOI: http:/ /dx.doi.org/10.1590/abd1806-4841.20185767

\begin{abstract}
BACKGROUND: Cutaneous melanoma accounts for up to $80 \%$ of deaths caused by skin cancer. Diagnostic suspicion and access to medical care and early intervention in suspected cases is vital to the patient's prognosis.

ОвлестіVES: To compare demographic and histopathological characteristics of primary cutaneous melanoma diagnosed in the public healthcare system (Sistema Único de Saúde SUS) and the private system in Joinville, Santa Catarina State, Brazil.

METHODS: This cross-sectional retrospective study analyzed primary cutaneous melanoma cases recorded from 2003 to 2014 in the resident population of Joinville. Ethical approval was obtained from the local Research Ethics Committee.

RESULTS: 893 cases of primary cutaneous melanoma were identified. Patients in the private system were mostly younger, while there were more elderly patients in the public healthcare system $(p<0.001)$. There was no statistically significant association between type of care (public/private) and gender or presence of multiple primary cutaneous melanomas. Histological diagnosis of superficial spreading melanoma was more common in patients treated in private healthcare, while nodular melanoma was more frequent in patients in the public healthcare system $(\mathrm{p}<0.001)$. Mean Breslow depth in patients treated in private healthcare was $1.35 \mathrm{~mm}$, compared to $2.72 \mathrm{~mm}$ in the public system $(\mathrm{p}<0.001)$.

STUDY LIMITATIONS: This was a retrospective study using secondary databases.

CONCLUSIONS: thin cutaneous melanoma (in situ cutaneous melanoma and Breslow T1) showed the strongest association with the private healthcare system, while thick cutaneous melanoma was more frequent in the public system (Breslow category T3 and T4) $(\mathrm{p}<0.001)$.
\end{abstract}

Keywords: Health systems; Melanoma; Public health

\section{INTRODUCTION}

Cutaneous melanoma (CM) accounts for up to $80 \%$ of skin cancer deaths. ${ }^{1,2}$ The risk of developing metastatic melanoma and dying from $\mathrm{CM}$ is directly related to the phase of the disease at the time of diagnosis. ${ }^{3,4}$ Survival rates are based on the TNM classification (which assesses thickness of the primary tumor and presence of distant or lymph node metastatic disease) and vary significantly according to these aggravating factors. ${ }^{5}$ Thus, timely detection, assessment and management should be a high public health priority, and the dermatologist plays a crucial role in this process. ${ }^{6-8}$
In Brazil, epidemiological data on $\mathrm{CM}$ are limited at both the national and regional levels. ${ }^{9}$ According to the Brazilian National Cancer Institute (INCA), the projected crude rates in 2016 were 3.03 cases/100,000 men and 2.59/100,000 women, with higher estimated rates in the South of Brazil and higher mortality in men. ${ }^{10-11}$

In 2014, the municipality (county) of Joinville had 554,601 inhabitants, predominantly white (86\%), with an important young contingent $\left(30 \% \leq 20\right.$ years of age).$^{12}$ Joinville has a high CM incidence by Brazilian standards, with an upward trend and higher

\footnotetext{
Received 21 March 2016.

Accepted 24 May 2017.

* Work conducted at Universidade da Região de Joinville, Joinville (SC), Brazil.

Financial Support: None.

Conflict of Interest: None.

Dermaclinic Clínica de Dermatologia de Joinville, Joinville (SC), Brazil.

Medical student, Universidade da Região de Joinville, Joinville (SC), Brazil.

Department of Medicine, Universidade da Região de Joinville, Joinville (SC), Brazil.

Dermatology Service, Universidade Federal do Rio Grande do Sul, Porto Alegre (RS), Brazil.
}

MAILING ADDRESS:

Raquel Bissacotti Steglich

E-mail: raquelsteglich@yahoo.com.br

(C)2018 by Anais Brasileiros de Dermatologia 
incidence in women. From 2003 to 2006, Joinville's CM age-standardized incidence (2010 World population standard) was 11.8 per 100,000 persons, and from 2011 to 2014 it was 17.5, an increase of $48.3 \%(\mathrm{p}<0.05) .{ }^{13}$

Given this background, the study aimed to compare the demographic and histopathological characteristics of primary CMs diagnosed in patients in the public healthcare system (SUS) with those of private patients (health plans, health insurance, out-of-pocket) in Joinville. The purpose was to identify differences between these patient groups and thus help orient preventive measures, especially early diagnosis.

\section{METHODS}

This retrospective cross-sectional study analyzed cases of primary CM recorded from January 2003 to December 2014 in the Joinville population. The study period was selected due to the availability of systematic records on CM in the laboratories.

Pathology reports were collected on all cases of primary CM diagnosed in the only three anatomical pathology laboratories in the municipality, which are responsible for diagnosis in patients residing in Joinville and the region. In two laboratories, data were collected with the descriptors "melanoma" and "malignant lentigo" in the field for diagnosis and the descriptor "skin and/or cutaneous" in the field "affected organ" to identify and select the reports for all CMs in the electronic databases. The third laboratory provided its diagnostic record books for the years 2003 to 2007 for manual collection, while in subsequent years the data were collected as in the first two laboratories.

Patients' municipality of residence was not available in half of the pathology reports. We thus searched for this information in the user database of the Unified Health System (SUS), under the responsibility of the Municipal Health Department, the database of patients covered by a health plan, and the place of origin of the specimen (specialty outpatient clinics of the SUS and private physicians' offices). Patients' full name and date of birth were used to confirm the address and to identify the existence of multiple pathology reports for the same $\mathrm{CM}$ (which can happen when the diagnosis is the result of an incisional biopsy followed by tumor excision or expansion of the margins). For patients with CM reports resulting from incisional biopsy and subsequent excision, the study used the report with the greatest Breslow depth. The study had no access to patients' medical charts or to the patients themselves. The histological specimens were not reviewed, assuming as correct the diagnosis and descriptions found in the pathology reports.

Inclusion criteria were residence in Joinville and having a diagnosis of primary $\mathrm{CM}$ during the study period. Exclusion criteria were: pathology reports on specimens from other cities; cases of melanoma of other organs and tissues; reports on revision of slides from surgical pathology; reports suggestive of melanoma, but with an inconclusive diagnosis, without immunohistochemical confirmation; reports on residual tumor or expansion of surgical margins.

After applying the inclusion and exclusion criteria to the 1,548 existing reports, 655 reports (42.3\%) were excluded, as follows: reports on patients residing in other cities (390; 25.2\%), melanoma metastases $(46 ; 3.0 \%)$, duplicate reports (expansion of margins, inci- sional biopsy followed by complete excision) (144; 9.30\%), revision of sides or complementary immunohistochemistry (40;2.6\%), and other reasons (e.g., inconclusive reports, other neoplasms, melanomas of other organs) $(35 ; 2.3 \%)$.

The procedures are believed to have included all cases of $\mathrm{CM}$ in patients residing in Joinville, making this a population-based study.

Data were keyed into Excel 2011 and later exported to SPSS v.18.0 for the statistical analysis. Categorical variables were described as frequencies and percentages and quantitative variables as mean with standard deviation, median, and interquartile range. Chi-square test was used to compare the categorical variables, and adjusted residuals analysis was used to locate the differences indicated by this test. Residuals with absolute values greater than 1.96 were considered statistically significant. Multivariate logistic regression was used to adjust for the age difference between the two patient groups (public versus private). Mann-Whitney test was used to compare the median Breslow depth. Statistical significance was set at 0.05 .

The Breslow index, which assesses tumor thickness in millimeters, was categorized as T1 $(\leq 1.0 \mathrm{~mm}), \mathrm{T} 2(1.01-2.0 \mathrm{~mm}), \mathrm{T} 3(2.01$ $-4.0 \mathrm{~mm}), \mathrm{T} 4$ (>4.0mm), and not recorded or compromised. ${ }^{5}$

Patients were categorized by gender (female/male) and grouped by age bracket as young (under 60 years) or old (60 years or older), according to the WHO definition. ${ }^{14}$

The study was approved by the Institutional Review Board of Universidade da Região de Joinville, under case review no. 830.587 .

\section{RESULTS}

During the study period, 893 primary CMs were identified, with a predominance in women (507 or $56.8 \%$ ). Mean age of $\mathrm{CM}$ patients was 54.6 years $(\mathrm{SD}=16.5)$. There was no statistical difference between the two groups (public versus private) according to gender $(p=0.264)$. There was a predominance of younger patients in the private system and older patients in the public system $(p<0.001)$. Individuals with multiple primary CMs predominated in the public system $(\mathrm{p}<0.001)$ (Table 1$)$.

There was a statistically significant difference in histological type according to type of care, with superficial spreading melanoma (SSM) found more often in private patients $(\mathrm{p}<0.001)$ and nodular melanoma $(\mathrm{NM})$ in patients in the public system $(\mathrm{p}<0.001)$ (Table 2$)$.

Median Breslow depth in private patients was $0.75 \mathrm{~mm}$ (interquartile range $=0.8850$ ), compared to public patients with $1.30 \mathrm{~mm}$ (interquartile range $=2.9075$ ), a statistically significant difference $(\mathrm{p}<0.001)$.

Table 3 shows the statistically significant association between type of healthcare service and Breslow depth $(p<0.001)$. According to adjusted residuals analysis, the strongest associations were between private care and in situ $\mathrm{CM}$ and Breslow $\mathrm{T} 1$, and between the public system and Breslow depths T3 and T4.

In the logistic regression analysis, the variables that showed an association with the type of healthcare system coverage were patient's age and histological level. Patients over 60 years of age had 1.64 times higher odds of treatment in the public healthcare system when compared to patients under 60 years, independently of the patient's histological level. 
Patients with T1 tumors did not differ significantly from in situ tumors in relation to type of healthcare system coverage. Patients with $\mathrm{T} 2$ tumors had 1.75 times higher odds of treatment in the public healthcare system, compared to in situ patients. In patients with thicker tumors (Breslow T3 and T4), the odds of coming from the public system were more than double (3.79 and 3.80 times, respectively) when compared to in situ patients.

Logistic regression showed that the association between histological level and type of healthcare system coverage was independent of the patient's age. In other words, the association remained even after adjusting for age. Table 4 shows the adjusted logistic regression.

\section{DISCUSSION}

In our study, $59 \%$ of individuals with CM were treated in private care (health plans, health insurance, out-of-pocket). This percentage is higher than the combined coverage rate for private health plans and health insurance as a whole in Joinville, which is $41 \%$ of the population according to the National Supplementary Healthcare Agency (ANS). ${ }^{15}$ This overall coverage, some $15 \%$ high-

\begin{tabular}{|c|c|c|c|c|c|c|}
\hline \multirow[t]{2}{*}{ Type of healthcare system } & \multirow[b]{2}{*}{$\mathbf{N}$} & \multicolumn{2}{|c|}{ Private } & \multicolumn{2}{|c|}{ Public } & \multirow[t]{2}{*}{ p-value ${ }^{*}$} \\
\hline & & $\mathbf{N}$ & $(\%)$ & $\mathbf{N}$ & $(\%)$ & \\
\hline Total & 893 & 526 & $(58.9)$ & 367 & $(41.1)$ & \\
\hline Gender & & & & & & 0.264 \\
\hline Female & 507 & 290 & $(57.2)$ & 217 & $(42.8)$ & \\
\hline Male & 386 & 236 & (61.1) & 150 & $(38.9)$ & \\
\hline Age bracket (years) & & & & & & $<0.001$ \\
\hline Young (0-59) & 546 & 352 & $(64.5)$ & 194 & $(35.5)$ & \\
\hline Old $(\geq 60)$ & 347 & 174 & (50.1) & 173 & (49.9) & \\
\hline Multiple CMs & & & & & & 0.999 \\
\hline Yes & 127 & 52 & $(40.9)$ & 75 & $(59.0)$ & \\
\hline No & 766 & 474 & (61.9) & 292 & $(38.1)$ & \\
\hline
\end{tabular}

Note: ${ }^{*}=$ Chi-square test.

TABLE 2: Distribution of CMs by histological type in patients treated in private versus public healthcare system (SUS)

\begin{tabular}{|c|c|c|c|c|c|}
\hline \multirow[b]{2}{*}{ Histological type } & \multirow[b]{2}{*}{$\mathbf{N}$} & \multicolumn{2}{|c|}{ Private } & \multicolumn{2}{|c|}{ Public } \\
\hline & & $\mathbf{N}$ & $(\%)$ & $\mathbf{N}$ & $(\%)$ \\
\hline LMM & 91 & 57 & $(10.9)$ & 34 & (9.4) \\
\hline DM & 5 & 2 & $(0.4)$ & 3 & $(0.8)$ \\
\hline ALM & 10 & 5 & $(1.0)$ & 5 & $(1.4)$ \\
\hline NMM & 9 & 6 & (1.1) & 3 & $(0.8)$ \\
\hline NM & 168 & 63 & $(12.1)$ & 105 & $(28.9)^{*}$ \\
\hline Melanoma, NOS & 86 & 46 & $(8.8)$ & 40 & $(11.0)$ \\
\hline SSM & 516 & 343 & $(65.7)^{*}$ & 173 & $(47.7)$ \\
\hline Total ${ }^{* *}$ & 885 & 522 & $(100.0)$ & 363 & (100.0) \\
\hline
\end{tabular}

Note: Chi-square test - p-value $<0.001 ;{ }^{*}=$ adjusted residuals analysis; ** = missing data. $\mathrm{LMM}=$ lentigo maligna melanoma; DM = desmoplastic melanoma; ALM = acral lentiginous melanoma; NMM = nevoid malignant Note: Chi-square test - p-value $<0.001 ; *=$ adjusted residuals analysis; ${ }^{* *}=$ missing data. LMM $=$ lentigo malign
melanoma; NM = nodular melanoma; SSM = superficial spreading melanoma; NOS = not otherwise specified.

TABLE 3: Distribution of CMs in patients treated in private versus public healthcare system (SUS), according to histological level

\begin{tabular}{|c|c|c|c|c|c|}
\hline \multirow[b]{2}{*}{ Histological type } & \multirow[b]{2}{*}{$\mathbf{n}$} & \multicolumn{2}{|c|}{ Private } & \multicolumn{2}{|c|}{ Public } \\
\hline & & $\mathbf{n}$ & $(\%)$ & n & $(\%)$ \\
\hline In situ & 203 & 138 & $(27.1)^{*}$ & 65 & $(18.6)$ \\
\hline $\mathrm{T} 1$ & 369 & 250 & $(49.0)^{*}$ & 119 & (34.1) \\
\hline $\mathrm{T} 2$ & 112 & 62 & $(12.1)$ & 50 & $(14.3)$ \\
\hline $\mathrm{T} 3$ & 81 & 28 & (5.5) & 53 & $(15.2)^{*}$ \\
\hline $\mathrm{T} 4$ & 94 & 32 & (6.3) & 62 & $(17.8)^{*}$ \\
\hline Total $^{* *}$ & 859 & 510 & (100.0) & 349 & $(100.0)$ \\
\hline
\end{tabular}

Note: Chi-square test $-\mathrm{p}$-value $<0.001 ; *$ adjusted residuals analysis; ${ }^{* *}=$ missing data 


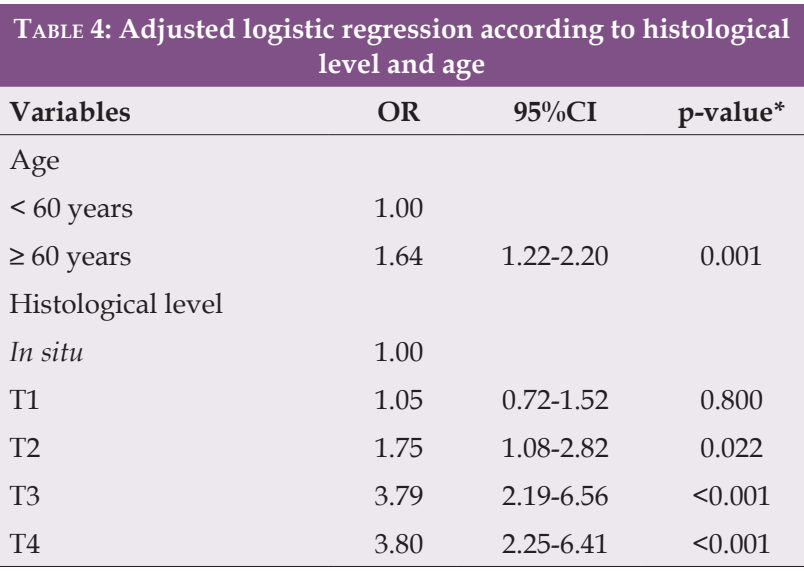

Notes: $\mathrm{OR}=$ odds ratio; $95 \% \mathrm{CI}=95 \%$ confidence interval; $*$ = p-value, logistic regression

er than Brazil's national average, along with high socioeconomic indices such as mean per capita income, urbanization rate (96.6\%), human development index (HDI) (0.809), and schooling, suggest that this population has a higher living standard than the Brazilian national average, and that it consists mostly of wage-earning urban workers with formal employment contracts and labor benefits. ${ }^{15-19}$

Such characteristics function as protective factors against the barriers to use of the SUS and provide greater ease in access to specialized treatments and tests. ${ }^{16,17}$

Our study design did not allow identifying the reason why the majority of patients diagnosed with CM were diagnosed in private practice. Patients' difficulties in using the public healthcare system (SUS) exclusively are known to potentially cause delays in diagnosis and treatment. ${ }^{17}$ Patients thus trek through the health system, mixing different types of care, public and private, to the extent that they encounter difficulties in access to specialized care. This situation may lead SUS patients to seek medical care and pathology tests by paying out of pocket, as if they were from the private system. The barriers to use of services in the SUS can result in delays in diagnosis, and thus thicker CMs and even death. Another possible explanation for the predominance of patients from the private system in our series is underreporting of cases among SUS patients, as observed by Hoey et al. (2007) in patients with non-melanoma skin cancer (NMSC), among whom those from lower socioeconomic groups were less likely to seek medical care. ${ }^{20}$

In our series, patients in private care had more in situ and Breslow T1 cutaneous melanomas, while SUS patients had more $\mathrm{T} 3$ and T4 tumors. The comparison of median Breslow in the two groups showed the same result. Various studies have shown a positive correlation between thicker tumors at diagnosis and worse socioeconomic status. ${ }^{21-23}$ Haenssle et al. (2015) found that higher educational level was a protective factor against higher-grade $\mathrm{CM}$ and that the delay in diagnosis and greater tumor thickness occurred in older patients, men, and those with less schooling. ${ }^{22}$ Mayer et al. (2014) observed a higher risk of thick tumors ( $>2 \mathrm{~mm}$ ) in low-income patients. ${ }^{23}$ Population-based studies have called attention to the fact that although the incidence of $\mathrm{CM}$ is significantly higher in patients with high income and high educational level, the prognosis is worse in patients with low socioeconomic status, low schooling, and un- employment. ${ }^{20,22}$ It is worrisome that the longitudinal trend in the characteristics of patients and CMs in recent years has shown a higher increase in the incidence of Breslow T4 tumors in individuals with lower socioeconomic status and those over 65 years of age. . $3,24^{24}$

Among the patients seen in the public Unified Health System (SUS), there was a predominance of the nodular melanoma histological type and elderly patients, while superficial spreading melanoma histological type and younger age were more common in private patients. A study in the United States also found an association between low socioeconomic status and nodular melanoma subtype and Breslow T4. Nodular melanoma accounted for only $14 \%$ of all the CMs in the study population, but it included a high proportion (37\%) of fatal cases. ${ }^{23}$

It is worrisome that lower-income patients, who are mostly those treated exclusively in the public health system, have a diagnosis of more advanced stages of cutaneous melanoma and with worse prognosis. This reveals the inequality in Brazil's national health system, which formally recommends equal access to healthcare but is unable to meet this promise, thus excluding the more socially vulnerable population from timely access. ${ }^{22}$

The difficulty in access to specialists also contributes to worse prognosis. Studies have shown that dermatologists make the diagnosis earlier than physicians from other specialties, ${ }^{20,22-25}$ and that their patients survive longer. ${ }^{22}$ Residing in an area with a high density of dermatologists is independently associated with a diagnosis of thin $\mathrm{CM}^{2}{ }^{24}$ Residing in an area with a low density of dermatologists and having a CM diagnosed by a non-dermatologist were independently associated with increased mortality from $\mathrm{CM}{ }^{8}$ Patients that consulted a dermatologist were also more likely to perform self-examination of the skin. ${ }^{8}$ Thus, studies show that dermatologists, as expected due to their training in the assessment of skin lesions, with or without dermoscopy, are more likely to diagnose and adequately manage pigmented lesions, when compared to all other medical specialists.

Participation in specialized screening programs in dermoscopy was the single strongest factor associated with diagnosis of thin CMs. Patients enrolled in these programs usually have an increased risk of $\mathrm{CM}$, belong to younger age brackets at the time of diagnosis, and have more schooling. ${ }^{22}$

Our findings on cutaneous melanoma and socioeconomic factors require further elucidation in order to improve early detection and eliminate the socioeconomic disparities in access to diagnosis and treatment. The creation and improvement of compulsory reporting systems for cancers can help form a reliable population-based registry, crucially important for orienting interventions targeted at the population's behavioral characteristics and changes in public health policies.

Finally, early diagnosis of cutaneous melanoma reduces treatment costs, generating considerable savings for both the public healthcare system (SUS) and the private system. The funds resulting from such savings could be applied to programs for prevention and early diagnosis of skin cancer, as well as research on new techniques and drugs to treat these patients. ${ }^{26,27}$

The study's main limitation was its retrospective design using a secondary database. Our data may be underestimated since 
some pathology specimens were sent from private offices to laboratories located outside the municipality, and some local residents may have gone elsewhere for diagnosis and treatment. In addition, some patients diagnosed with CM may have died. The data may also be overestimated because users of the public healthcare system (SUS) residing in other cities may have claimed the address of relatives or friends in order to gain access to medical services in Joinville, which is known as a reference in quality healthcare. However, given the size of the current study's case series, we believe that any possible bias was minimal and did not interfere greatly in the findings.

The exact mechanisms that explain our results are still not clear, but the difficulties faced by Brazil's public healthcare system (organizational, operational, and structural), along with the population's limited knowledge of cutaneous melanoma, less willingness to participate in screening programs, and other lifestyle factors not analyzed in the current study may have contributed to late diagnosis in the group of patients seen in the public health system. More knowledge is needed on the role of these various sociodemographic, clinical, and behavioral factors, along with greater Breslow depth, in relation to late diagnosis of cutaneous melanoma both by healthcare providers and patients.

\section{CONCLUSION}

We found an independent association between histological level as verified by the Breslow index and the type of healthcare system coverage $(p<0.001)$. Patients from the private healthcare system had thin cutaneous melanomas (in situ and Breslow T1), while patients seen exclusively in the public healthcare system (SUS) had thick cutaneous melanomas (Breslow T3 and T4).

\section{REFERENCES}

1. Cavarsan F. Epidemiologia do melanoma no Brasil. In: Wainstein A, Belfort F. Melanoma: prevenção, diagnóstico, tratamento e acompanhamento. 2. ed. São Paulo: Atheneu; 2014. p.11-22.

2. Azarjana K, Ozola A, Ruklisa D, Cema I, Rivosh A, Azaryan A, et al. Melanoma epidemiology, prognosis and trends in Latvia. J Eur Acad Dermatol Venereol. 2013;27:1352-9

3. Vries E, Bray F, Coebergh JW, Cerroni L, Ruiter DJ, Elder DE, et al. Malignant melanoma: introduction. In: LeBoit PE, Burg G, Weedon D, Sarasin A, editors. World Health Organization classification of tumours: pathology and genetics, skin tumours. 3. ed. Lyon: International Agency for Research on Cancer; 2006. p. 52-65.

4. Xing Y, Chang GJ, Hu CY, Askew RL, Ross MI, Gershenwald JE, et al. Conditional survival estimates improve over time for patients with advanced melanoma results from a population-based analysis. Cancer. 2010;116:2234-41.

5. Balch CM, Gershenwald JE, Soong SJ, Thompson JF, Atkins MB, Byrd DR, et al. Final Version of 2009 AJCC Melanoma Staging and Classification. J Clin Oncol. 2009;27:6199-206
6. Sidiropoulos M, Obregon R, Cooper C, Sholl LM, Guitart J, Gerami P. Primary dermal melanoma: a unique subtype of melanoma to be distinguished from cutaneous metastatic melanoma. J Am Acad Dermatol. 2014;71:1083-92.

7. Krige JE, Isaacs S, Hudson DA, King HS, Strover RM, Johnson CA. Delay in the diagnosis of cutaneous malignant melanoma: a prospective study in 250 patients. Cancer. 1991;68:2064-8.

8. Cheng MY, Moreau JF, McGuire ST, Ho J, Ferris LK. Melanoma depth in patients with an established dermatologist J Am Acad Dermatol. 2014;70:841-6.

9. Battisti R, Nunes DH, Lebsa-Weber A, Schweitzer LC, Sgrott I. Evaluation of the epidemiological profile and the mortality rate of the patients with primary cutaneous melanoma in Florianopolis - SC, Brazil. An Bras Dermatol. 2009;84:335-42.

10. Inca.gov.br [Internet]. Brasil (Consolidado). Estimativas para 0 ano de 2016 das taxas brutas de incidência por 100 mil habitantes e do número de casos novos de câncer, segundo sexo e localização primária. Rio de Janeiro: Instituto Nacional do Câncer [acesso 11 Fev 2016]. Available at: http://www.inca.gov.br/ estimativa/2016/tableestados.asp?UF=BR 
11. Inca.gov.br [Internet]. Tipos de câncer: pele melanoma. Rio de Janeiro: Instituto Nacional do Câncer. [acesso 29 Ago 2015]. Available at: http://www2.inca.gov.br/ wps/wcm/connect/tiposdecancer/site/home/pele_melanoma.

12. Secretaria Municipal da Saúde de Joinville. População residente por unidade de saúde, por bairro, faixa etária e sexo. Joinville: Secretaria Municipal da Saúde; 2014.

13. Steglich RB, Coelho KMPA, Cardoso S, Gaertner MHCN, Cestari TF, Franco SC. Epidemiological and histopathological aspects of primary cutaneous melanoma in residents of Joinville, 2003-2014. An Bras Dermatol. 2018;93(1):45-53.

14. World Health Organization - WHO. Health statistics and information systems: Definition of an older or elderly person: Proposed Working Definition of an Older Person in Africa for the MDS Project. Geneva, WHO, 2007. [accessed 10 Nov 2014]. Available at: http://www.who.int/healthinfo/survey/ageingdefnolder/en/

15. Ans.gov.br [Internet]. Informações em saúde suplementar TabNet. Rio de Janeiro: Agência nacional de saúde suplementar [accessed 16 Nov 2015]. Available at: http://www.ans.gov.br/anstabnet/cgibin/dh?dados/tabnet_br.def

16. Ibge.gov.br [Internet]. Pesquisa Nacional por Amostra de Domicílios. Análise de Resultados. Brasília: Instituto Brasileiro de Geografia e Estatística. [accessed 15 Nov 2015]. Available at: http://www.ibge.gov.br/home/estatistica/populacao/ trabalhoerendimento/pnad98/saude/analise.shtm

17. Assis MMA, Jesus WLA. Acesso aos serviços de saúde: abordagens, conceitos, políticas e modelo de análise. Ciênc Saúde Coletiva. 2012:17:2865-75.

18. Cidades.ibge.gov.br. [Internet]. IBGE. Cidades. Santa Catarina. Joinville. Histórico. 2016 [accessed 9 Nov 2015]. Available at: http://www.cidades.ibge.gov.br/ painel/historico.php?lang $=\& \operatorname{codmun}=420910 \&$ search $=$ santacatarina $\mid$ joinville |infograficos:historico.

19. Saude.joinville.sc.gov.br [Internet]. Secretaria Municipal da Saúde de Joinville. Plano Municipal de Saúde 20142017. Joinville: Secretaria Municipal de Saúde de Joinville. [accessed 15 Nov 2015]. Available at: https://saude.joinville.sc.gov. br/public/portalsaudeadm/imagens/conteudo/PMS201417versaoPUBLICACAO04dez2013.pdf.

20. Hoey SE, Devereux CE, Murray L, Catney D, Gavin A, Kumar S, et al. Skin cancer trends in Northern Ireland and consequences for provision of dermatology services. Br J Dermatol. 2007;156:1301-7.
21. Singh SD, Ajani UA, Johnson CJ, Roland KB, Eide M, Jemal A, et al. Association of cutaneous melanoma incidence with area-based socioeconomic indicators United States, 2004-2006. J Am Acad Dermatol. 2011;65:S58-68.

22. Haenssle HA, Hoffmann S, Holzkamp R, Samhaber K, Lockmann A, Fliesser M, et al. Melanoma thickness: the role of patients' characteristics, risk indicators and patterns of diagnosis. J Eur Acad Dermatol Venereol. 2015;29:102-8.

23. Mayer JE, Swetter SM, Fu T, Geller AC. Screening, early detection, education, and trends for melanoma: current status (2007-2013) and future directions. J Am Acad Dermatol. 2014;71:611.e1-611.e10.

24. Barbe C, Hibon E, Vitry F, Le Clainche A, Grange F. Clinical and pathological characteristics of melanoma: a population-based study in a French regional population. J Eur Acad Dermatol Venereol. 2012;26:159-64.

25. Lebsa-Weber A, Nunes DH, Souza Filho JJ, Carvalho-Pinto CJ. A comparison of cutaneous melanoma cases diagnosed by different medical specialists. An Bras Dermatol 2007;82:311-5.

26. Souza RJSP, Mattedi AP, Rezende ML, Corrêa MP, Duarte EM. An estimate of the cost of treating melanoma disease in the state of Sao Paulo - Brazil. An Bras Dermatol. 2009;84:237-43.

27. Geller AC, Cantor M, Miller DR, Kenausis K, Rosseel K, Rutsch L, et al. The Environmental Protection Agency's National SunWise School Program: Sun protection education in US schools (19992000). J Am Acad Dermatol. 2002;46:683-9.

\section{AUTHORS CONTRIBUTION}

Raquel Bissacotti Steglich

\section{iD ORCID 0000-0001-6550-3715}

Statistical analysis; Approval of the final version of the manuscript; Conception and planning of the study; Elaboration and writing of the manuscript; Obtaining, analyzing and interpreting the data; Effective participation in research orientation; Intellectual participation in propaedeutic and/or therapeutic conduct of the cases studied; Critical review of the literature; Critical review of the manuscript.

Silvana Cardoso

(iD) ORCID 0000-0002-0025-9149

Elaboration and writing of the manuscript; Obtaining, analyzing and interpreting the data Maria Helena da Costa Naumann Gaertner (iD) ORCID 0000-0002-8970-3604

Elaboration and writing of the manuscript; Obtaining, analyzing and interpreting the data Karina Munhoz de Paula Alves Coelho $\quad$ (iD) ORCID 0000-0002-4743-8742 Approval of the final version of the manuscript; Obtaining, analyzing and interpreting the data; Critical review of the manuscript

\section{Tania Ferreira Cestari \\ D ORCID 0000-0003-3001-0202}

Approval of the final version of the manuscript; Conception and planning of the study; Elaboration and writing of the manuscript; Obtaining, analyzing and interpreting the data; Effective participation in research orientation; Intellectual participation in propaedeutic and/or therapeutic conduct of the cases studied; Critical review of the literature; Critical review of the manuscript

Selma Cristina Franco

ORCID 0000-0002-0323-2988

Statistical analysis; Approval of the final version of the manuscript; Conception and planning of the study; Elaboration and writing of the manuscript; Obtaining, analyzing and interpreting the data; Effective participation in research orientation; Intellectual participation in propaedeutic and/or therapeutic conduct of the cases studied; Critical review of the literature; Critical review of the manuscript

How to cite this article: Steglich RB, Cardoso S, Gaertner MHCN, Coelho KMPA, Cestari TF, Franco SC. Differences in the diagnosis of primary cutaneous melanoma in the public and private healthcare systems in Joinville, Santa Catarina State, Brazil. An Bras Dermatol. 2018;93(4):507-12. 